

\section{Imaginarios y estrategias decoloniales}

\section{Artículo de investigación}

Recibido: 20 de agosto de 2017

Aprobado: 5 de octubre de 2017

Raúl Moarquech Ferrera-Balanquet

Escuela Superior de las Artes de Yucatán -

Laboratorio Cartodigital, México

raulmoarquech@gmail.com

Cómo citar este artículo: Ferrera- Balaquet, Raúl Moarquech (2018). Imaginarios y estrategias decoloniales. Estudios Artísticos: revista de investigación creadora, 4 (4) pp.42-61.DOI: https://doi. org/10.14483/25009311.12932

$<$

Las Aguas Sagradas de La Llorona (2004), mural de Juana Alicia Araiza. Fotografía: cortesía de Juana Alicia Araiza.

\section{Resumen}

Enunciando el delinking de la matriz moderna/ colonial, este artículo imagina un territorio crítico teórico creativo partiendo de la aesthesis decolonial con el fin de dialogar con una serie de hacedores culturales que emplean estrategias creativas decoloniales en proyectos creativos. Un acercamiento a la exposición Haceres Decoloniales (2015) realizada en Bogotá, ofrece la oportunidad de conversar sobre el hacer creativo de Benvenuto Chavajay, Rosa Tisoy Tandoy y Marco Alonso Roa. Los efectos de la colonialidad sonora conllevan a dialogar con la artista maya k' iche Sandra Monterroso y el creador maya yucateco Isaac Carrillo Can. Discursamos sobre el proyecto Espejo Negro (2010) de Pedro Lasch y el mural Las Aguas Sagradas de La Llorona (2004) de la artista xicana Juana Alicia. Terminamos con una interpretación crítica sobre el proyecto Mariposa Memoria Ancestral (2013-2015), y el performance multidisciplinario Whip It Good (2013) de la artista danesa trinitobaguense Jeannette Ehlers.

\section{Palabras clave}

Desenganche, aestesis, decolonial, estrategias, creadores, sentipensar.

\section{Imaginaries and Decolonial Strategies}

\footnotetext{
Abstract

Enunciating the delinking of the modern / colonial matrix, this article imagines a critical- theoretical-creative territory starting from the decolonial aesthesis in order to establish a dialogue with a series of cultural agents that employ creative decolonial strategies in artistic projects. An approach to the exhibition Haceres Decoloniales (2015) held in Bogotá, offers the opportunity to talk about the
} 
creative work of Benvenuto Chavajay, Rosa Tisoy Tandoy and Marco Alonso Roa. The effects of sound colonialism entail a dialogue with the Maya K'iche artist Sandra Monterroso and the Yucatec Mayan creator Isaac Carrillo Can. We delve into the project Espejo Negro (2010) by Pedro Lasch and the mural Las Aguas Sagradas de La Llorona (2004) by the xicana artist Juana Alicia. We end with a critical interpretation of the Mariposa Memoria Ancestral (2013-2015) project, and the multidisciplinary performance Whip It Good (2013) by the Danish Trinidadian artist Jeannette Ehlers.

\section{Keywords}

Disengagement, aesthesis, decolonial, strategies, creators, thinking-feeling.

\section{Imaginaires et stratégies décoloniales}

\section{Résumé}

En reliant la déconnexion de la matrice moderne / coloniale, cet article imagine un territoire créatifthéorique-critique à partir de l'aesthésis décoloniale, afin de dialoguer avec une série d'acteurs culturels qui utilisent des stratégies décoloniales créatives dans des projets créatifs. Une approche de l'exposition Haceres Decoloniales (2015) tenue à Bogotá, offre l'occasion de parler du travail créatif de Benvenuto Chavajay, Rosa Tisoy Tandoy et Marco Alonso Roa. Les effets de la colonialité sonore impliquent un dialogue avec l'artiste maya k'iche Sandra Monterroso et le créateur maya yucatècque Isaac Carrillo Can. Nous parlons du projet Espejo Negro (2010) de Pedro Lasch et de la peinture murale Las Aguas Sagradas de La Llorona (2004) de l'artiste chicane Juana Alicia. Nous terminons avec une interprétation critique du projet Mariposa Memoria Ancestral (2013-2015) et la performance pluridisciplinaire Whip It Good (2013) de l'artiste danois né en Trinité-et-Tobago Jeannette Ehlers.

\section{Mots clés}

Désengagement, aesthésis, décoloniale, stratégies, créateurs, senti-penser.

\section{Imaginários e estratégias decoloniais}

\section{Resumo}

Enunciando o delinking da matriz moderna/colonial, este artigo imagina um território crítico, teórico, criativo partindo da aesthesis decolonial com a finalidade de dialogar com uma série de produtores culturais que empregam estratégias criativas decoIoniais em projetos criativos. Uma aproximação da exposição Haceres Decoloniales (2015) realizada em Bogotá, oferece a oportunidade de conversar sobre o fazer criativo de Benvenuto Chavajay, Rosa Tisoy Tandoy e Marco Alonso Roa. Os efeitos da colonialidade sonora implicam um diálogo com a artista maia k' iche Sandra Monterroso e o criador maia yucateco Isaac Carrillo Can. Abordamos o projeto Espejo Negro (2010) de Pedro Lasch e o mural Las Aguas Sagradas de La Llorona (2004) da artista chicana Juana Alicia. Finalizamos com uma interpretação crítica do projeto Mariposa Memoria Ancestral (2013-2015), e a performance multidisciplinar Whip It Good (2013) da artista dinamarquesa trinitino-tobaguense Jeannette Ehlers.

\section{Palavras-chave}

Desengate, aestesis, decolonial, estratégias, criadores, sentipensar.

\section{luiariska rurai dikukuniales}

\section{Maillallachiska}

Maia rimai delinking ñugpa rurai kulunial, kai riai iuichimi sug alpa unschai kilkaska kaiariska aesthesis decolonial chasa rimangapa sug ruragkunawa tsobajankunami suma iuirispa dikuluniales sug ruraikuna uiñachiska, kaiaia kawangapa haceres decoIoniales (2015), ruraska Bugutapi, kai kumbidami parlangapa rurai uiñachiska Benvenuto Chavajay, Rosa Tisoy Tandioy y Marco Alonso Roa. Kai ruraskamanda kulunialidad uiariska apanmi Rimangapa. Kai Maya k iche Sandra Monterroso; uiñachidur Maya yucateco Isaac Carrillo Kan. Rimaskanchimi ispiju iamanda (2010) de Pedro Lasch, iunchiska wakaski iakukuna (2014) i sug xicana Juana Alicia. Tukuchiskanchi rimai allí ruraskamanda mariposamanda ñugpamanada iuia (2013- 2015) i suma ruraikunamanda whip it Good (2013) sug mama maitsu Danessa Trinitouamense Jeannette Ehlers.

\section{Rimangapa Ministidukuna}

Kacharichi, aestesisi dikulunial ruraikuna, uiñachiskakuna uiarispa i sitirispa. 


\section{Navegando el desligue de la estética moderna colonial}

Indagar en los mecanismos de la matriz moderna/ colonial vislumbra las estructuras (espacio tridimensional, tiempo progresivo, historia cronológica, movimiento lineal, sonido escalado) que definen la razón universal científica de la matriz anglo-eurocentrada: la operatividad del espacio cartesiano del cubo y la perspectiva central, la progresión temporal y su fantasía de desarrollo, la ficción en la cronología histórica, la linealidad euclidiana como base del movimiento direccional y la escala de sonidos eurocentrada. Dentro de las características formales de la matriz, quiero acentuar las clasificaciones estéticas, de género y raciales kantianas (Kant, 1767, p. 2011) las cuales aún hoy, dominan la lógica espacial cartesiana racionalista y la estética anglo-eurocéntrica que condicionan la producción de la literatura, el arte y la crítica occidental / universal / global.

Desengancharnos de la epistemología occidental significa decolonizar los principios naturalizados por el occidentalismo en los cuales el sentir, el conocimiento y el hacer son construidos, tanto en la formación disciplinaria como en la ideología de los discursos en la esfera pública. El desligue propone la estrategia de aprender a desaprender la matriz moderno/colonial, pues desde ese ejercicio logramos formular una teoría crítica que nos lleve a proyectar un desprendimiento de los conceptos críticos de Immanuel Kant y Max Horkheimer.

Es necesario apuntar hacia la decolonización epistémica y desmontar la complicidad oculta entre la retórica de la modernidad y la lógica de la colonialidad. Para que la teoría crítica corresponda con la de-colonización, necesitamos girar la geografía del conocimiento y refundirla (la teoría crítica) en los parámetros de la geopolítica y corpo-política del conocimiento" (Mignolo, 2007)

La acción de sentir, pensar y escribir desde el territorio propio nos ayuda imaginar las rutas posibles en la cuales podemos continuar el desprendimiento de la matriz moderno/colonial. Habitamos un territorio expandido más allá de la frontera con el espacio otro, no descrito, en el cual los artistas e intelectuales que asumimos la decolonialidad sentimos, pensamos, imaginamos, creamos y expresamos en capas y senderos múltiples, flujos en direcciones alternativas y geometrías variables e infinitas. Localizarnos en relación con los saberes ancestrales ayuda a describir la opresión desde la exterioridad del sistema moderno colonial, $y$ entonces logramos romper la distinción entre conocedor y conocimiento, al reconocer las formas propias ancestrales de pensar. En el andar desmontamos las lógicas opresoras y obstáculos que intentan frenar nuestra transformación radical y conjugamos el poder interétnico cultural que entrelaza y habita las experiencias del cuerpo tribu territorio en relación con el cosmos sentipensante; es decir, a la cosmovivencia. (Yampara, 2011).

Al poner en conversación diferentes campos de conocimientos, la oralidad y lo sonoro, como experiencias sensoriales y sensitivas inscritas en la palabra, en este ensayo que traza su propia geometría cósmica relacionada con la experiencia subjetiva, tribal y colectiva. Mignolo y Vázquez declaran que los procesos de expresión creativa de donde emerge la opción de la aesthesis decolonial son acciones radicales insurgentes:

\footnotetext{
... es una doble trayectoria, la del artista que ya no crea [siente, piensa, produce, expresa y se relaciona] desde los principios de la imitación (ni siquiera en el marco kantiano de lo hermoso y lo sublime), y es en ese andar donde una serie de discursos conceptuales y teóricos que por un lado proveen las lecturas decoloniales de la estética canónica occidental (moderna, postmoderna y altermoderna), y, por otro lado, proveen, junto con artistas que son teóricos y conceptualizadores a la vez (como se expresa claramente en este dosier), las trayectorias prospectivas del ser decolonizado y la decolonización del conocimiento.
}

Nombrar la aesthesis es una intervención radical lingüística del latín, en la cual se implica como el sentir ha sido colonizado desde la matriz moderna colonial que opera el control sobre los sentidos y la percepción de los sujetos colonizados; los mismos mecanismos con los cuales la matriz controla la economía, la política y el conocimiento (Mignolo y Vázquez, 2013).

La estética moderna originada en la noción kantiana de lo sublime, la centralización del objeto y la perspectiva central con su énfasis en lo visual ha relegado los niveles sensoriales como el aura, el gusto, el olfato, el tacto y la intuición a espacios periféricos. Jerarquizar la ideología de la visualidad y marginar los sentidos otros y su capacidades 


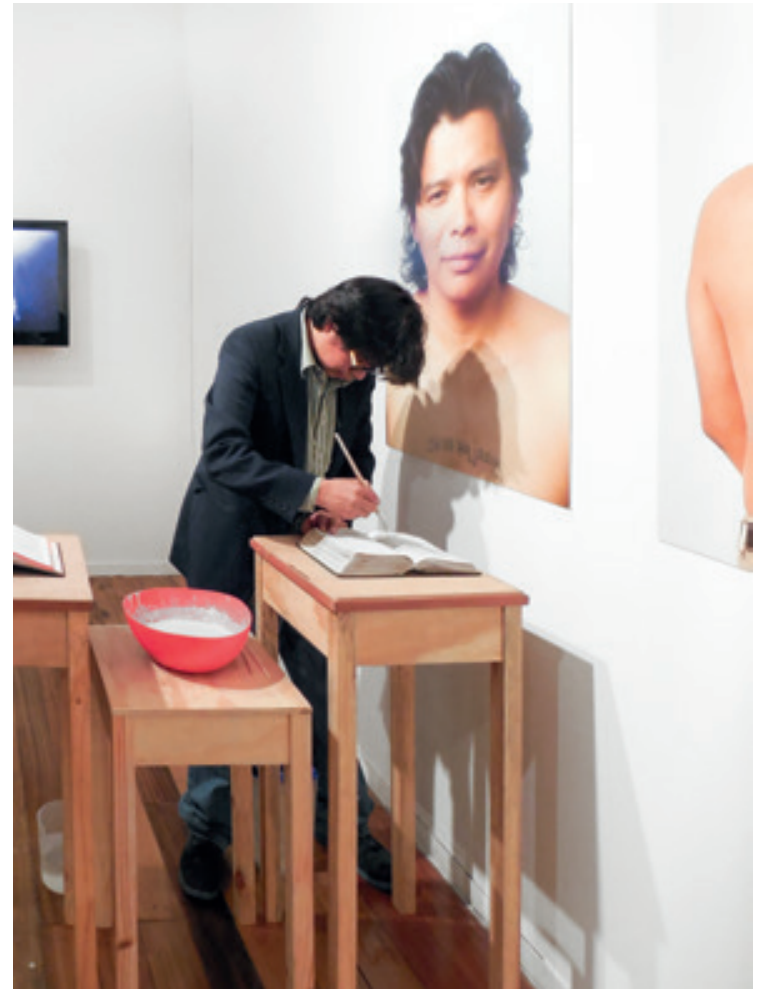

perceptivas, son algunos de los mecanismos de la lógica moderna, heteronormativa, patriarcal, colonial que predica el mercado del arte, los medios de comunicación y sus tecnologías de punta imbricadas en el discurso de progreso civilizador (Gómez, 2015). El ocularcentrismo ha condicionado la experiencia perceptiva y la memoria del sujeto creando sistemas de orden y clasificación que ahora se encuentran instalados en los subconscientes de muchxs. La colonialidad visual, al desplazar a los otros sentidos, crea una verticalidad en la cual se borra el aporte que los otros órganos sensoriales dan al pensar, imaginar y hacer.

La colonización de los sentidos contribuye a la administración del saber sobre el cuerpo como en el caso de la construcción del caníbal primitivo salvaje sodomita (Jáuregui, 2008); promueve la capacidad auditiva como lo ha implantado el lenguaje español, las armas y los perros feroces utilizados para las matanzas de indígenas (Estévez, 2012); el gusto que ha sido dominado a través de la cocina europea importada y la prohibición de sabores y
Retorno (2015), performance de Benvenuto Chavajay de la serie Borraduras, en Haceres Decoloniales. Fotografía: Raúl Moarquech Ferrera-Balanquet.

olores indígenas y africanos (Albán, 2010); ejerce la prohibición de rituales, ceremonia y cantos para controlar el tacto, la sonoridad y la expresión y así aniquilar la relación sensorial con el cosmos-natura (Barrera, 2009) y (Romero, 2012).

\section{Borrar escrituras coloniales para sanar el silencio}

En la exposición y evento académicos Haceres Decoloniales, ${ }^{1}$ tuve la oportunidad de dialogar,

\footnotetext{
1 El curador, crítico y profesor Pedro Pablo Gómez y el equipo de trabajo del Comité de Doctorado en Estudios Artísticos de la Facultad de Arte ASAB de la Universidad Distrital Francisco José de Caldas, (Bogotá, Colombia), organizaron el evento Haceres Decoloniales, realizado entre el 14 y el 31 de agosto de 2015, en la Facultad de Artes ASAB; en el cual se incluyó una exposición, performances y un encuentro académico. El evento abrió en la Sala de Exposiciones ASAB, con una ceremonia de Marco Alonso Roa y continuó con los performances Retorno de Benvenuto Chavajay, Suma kaugsai, chi sutepa pasarreco, lachii, asnai, winachii, trukai, tiagsamui de Rosa Tisoy Tandioy, Descendencia-Agencia de Daniel Brittany
} 


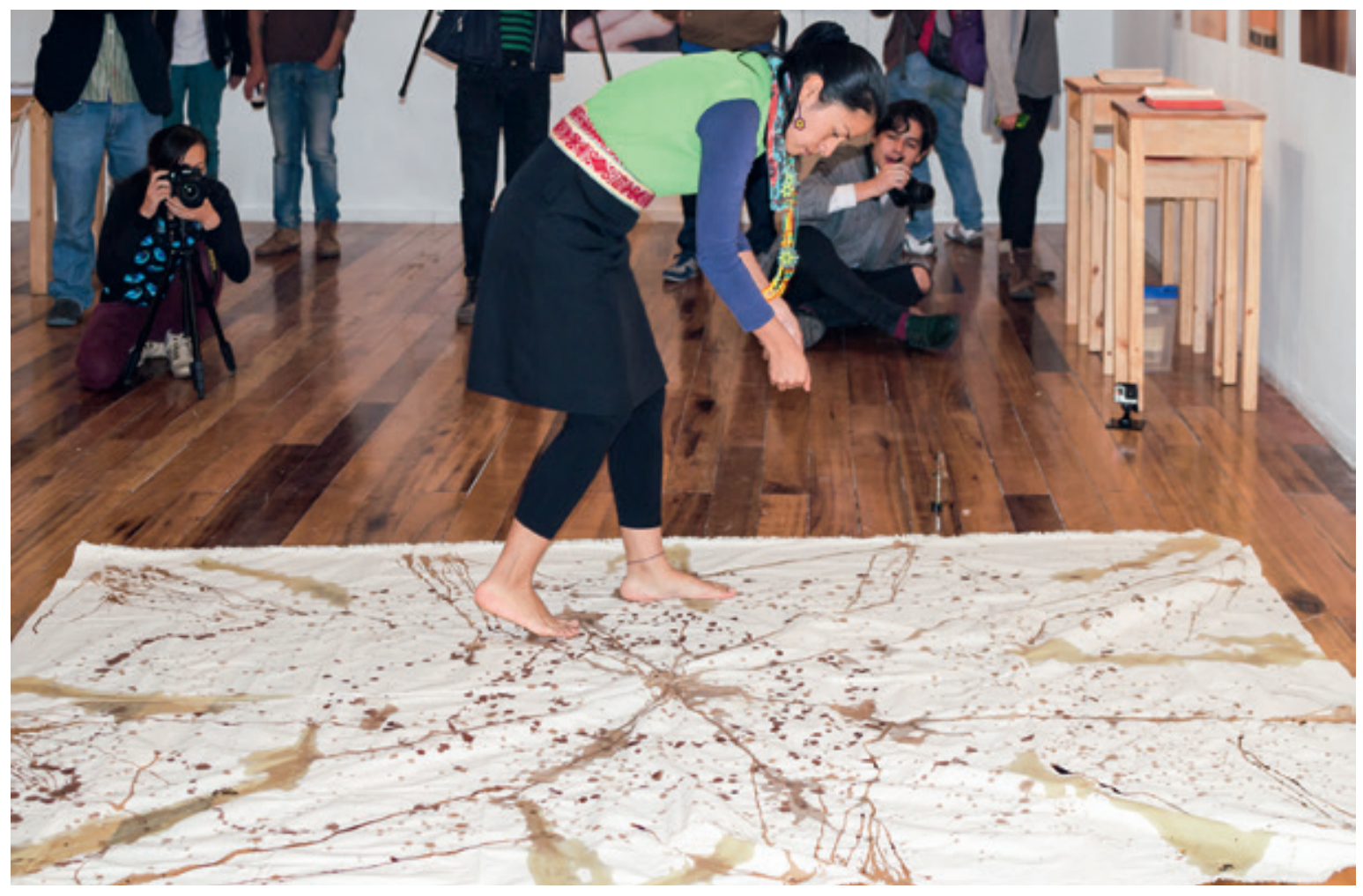

Suma kaugsai, chi sutepa pasarreco, iachii, asnai, winachii, trukai, tiagsamui (2015), performance Pintura olfativa de Rosa Tisoy presentado en Haceres Decoloniales. Fotografía: Raúl Moarquech Ferrera-Balanquet.

sanando durante el encuentro, al mismo tiempo que trabajamos en la recuperación de las memorias ancestrales, el apoyo espiritual, el intercambio de conocimientos y la extensión de proceso tribales comunitarios que afirmaron nuestra labor creativa radical insurgente y el compromiso para hacer visibles la vida sensitiva de nuestrxs ancestrxs y comunidades.

\section{La exposición y evento académico Haceres}

Decoloniales, incluyó la presentación de varias investigaciones de lxs compañerxs, en las cuales se reconoció la diseminación de saberes y espacios de crecimiento creativo que podrían servir para hacer un Doctorado en Estudios Artístico, como el que propone la Facultad de Arte ASAB. El diálogo pedagógico abrió las posibilidades para planear un proceso de aprendizaje que imbrique los estudios críticos, los imaginarios indígenas, las historias

Chávez y Mariposa Memoria Ancestral de Raúl Moarquech Ferrera-Balanquet. Para más información consulte «http://www. salasab.com/haceres-decoloniales» orgánicas del arte en América Latina, el Caribe y la diáspora latina en Estados Unidos.

En el prólogo a su traducción del Rabinal-Achi, Luis Cardoza y Aragón señala cómo en varias ocasiones, el texto maya k'quich ha sido mutilado o borrado por quienes, tratando de dar una coherencia de acuerdo a la lógica lineal occidental, han suprimido las repeticiones (Cardoza y Aragón, 1972). El artista maya t'zutujil Benvenuto Chavajay "reconoce que en mucha de sus obras el proceso de transculturización, tan pertinente para los pueblos originarios de las américas, mantiene una conexión epistémica Tz'utujil, que ha existido por siglos como testimonio de los viajes Tz'utujil" (Cornejo, 2013, p. 29). Consciente de cómo la colonialidad religiosa suprimió la espiritualidad maya cuando se tradujo al t'zutujil, su lengua indígena, textos cristianos, Chavajay realiza lo que él llama performance de borradura. Sobre biblias bilingües, el creador pinta con cal encima del texto en español y transforma la acción en un gesto radical que borra la colonialidad. Su serie de intervenciones 
se elaboran con la intención de sanar las heridas coloniales de la cultura t'zutujil. ${ }^{2}$ Para Chavajay, las acciones de borrar, inscribir y tatuar se inscriben en su quehacer decolonial.

Vengo de un pueblo donde se escucha a la tierra y a la piedra. Q'omanel en maya t'zutuil significa pintar, borrar, sanar y borro el castellano para regresar al lenguaje maya, el de mis ancestros, el de mi padre que sigue escuchando la piedra. Con esta acción conservo la lengua, la memoria y la cultura de mi pueblo (Chavajay, 2015). ${ }^{3}$

En la lógica colonial moderna, el acto de escribir borra el sonido de la palabra y la vuelve representación visual. Chavajay performancea la escritura en el gesto decolonial que busca resaltar la sonoridad del lenguaje ancestral maya $\mathrm{k}^{\prime}$ che.

En el andar por las calles bogotanas, la creadora Rosa Tisoy comentaba sobre la importancia en su obra de su cultura Inga y de Vichoy (Putumayo), el territorio donde nació, creció y a donde regresó después de terminar sus estudios de Artes Plásticas en la Universidad del Cauca. “... el lugar donde crecí es una vereda que hace parte de la construcción constante de mi vida, donde el conocimiento me impregna", ${ }^{4}$ comentó Rosa. “... y las costumbres, el valor de la palabra así como los recuerdos de mi niñez forman parte de la esencia de la afinidad por el querer hacer. El querer hacer es querer trasformar", afirmó, el tono melódico de su voz se mezcló con el viento que llegó desde la sierra para abrir el intercambio de saberes navegando los rumbos ancestrales - y el esfuerzo de Pedro Pablo Gómez-que nos trajeron a este territorio Muisca para sentipensar la creación desde nosotros, desde las memorias de Ixs abuelxs y desde la tierra

2 La serie Borraduras, ha sido presentada en varias exposiciones internacionales como Arte Nuevo InteractivA' 13 en Mérida, Yucatán y en Haceres Decoloniales en agosto de 2015, en Bogotá.

3 Palabras expresada en el evento académico de Haceres Descoloniales.

4 Durante nuestros andares por las calles bogotanas, Rosa

Tisoy compartió estas ideas. He decidido titular este apartado con el nombre de su performance, pintura olfativa, incluir parte del estatement que escribió para la exposición Haceres Decoloniales (2015) y traer su voz al texto para, de cierta forma, recrear aquellas profundas conversaciones, en la cuales también se encontraban Daniel Brittany Chávez, Benvenuto Chavajay y Martín Alonso Roa. que anuncia el tiempo cósmico y las conexiones ancestrales.

Gracias a la información que me brindó sobre su trabajo durante esas conversaciones, pude llegar a niveles muy profundos en el sentir la experiencia de su obra aquella tarde. "Es el pigmento natural que envuelve mucho más llenándolo de color y quizá de aroma. iSolo soy parte del todo que ya está!", me contestó cuando explicaba cómo comenzó a trabajar con la tierra, las semillas, las hojas y los árboles con los que lleva creando desde hace muchos años. Siempre pidiendo permiso a la Pachamama en un ritual de agradecimiento que conecta a su espíritu con todo, con la naturaleza, las energías cósmicas, el quehacer creativo.

Y esa tarde realizó su performance con unas semillas del árbol de Arrayán que crece en el Valle de Sibundoy, donde se encuentra su pueblo. "Su semilla cae en temporadas diferentes del año, cae en abundancia y es recogido por mis manos. Ella es de color oscuro, casi violeta, con aroma indescriptible." Rosa, extrajo de su bolsa de colores tejida por las abuelas de su tierra, las semillas del Arrayán. Su olor me transportó por los rumbos aymaras del sur y me indicó que el performance ya había comenzado en ese compartir de experiencias.

Pensar en, con y desde la tierra es pensar en, con y desde el cosmos; con los ciclos astronómicos de las wiwas, las estrellas que aparecen y desaparecen en el firmamento marcando el tiempo de las Iluvias, el tiempo de la fertilidad de los árboles y las plantas, el ciclo procreativo de los animales y los peces. Y así va Rosa por los caminos del valle encontrando el conocimiento de la tierra, las semillas, las hojas, las plantas, la medicina que cura, los colores y olores. Luego llega a la ciudad para compartir un poco de vida sensitiva putumaya en su performance de Pintura olfativa y convierte su hacer en una experiencia sentida.

Al comienzo de la performancia, un pedazo de tela -lienzo rústico, de aproximadamente cinco metros de largo por tres de ancho- se encontraba extendido junto a la pared. Rosa, cuidadosamente se quitó los zapatos y extrajo de su bolsa tejida los frascos donde había mezclado el extracto de las semillas con los aceites. En un ritual semejante a una danza, comenzó a rociar el lienzo desde 


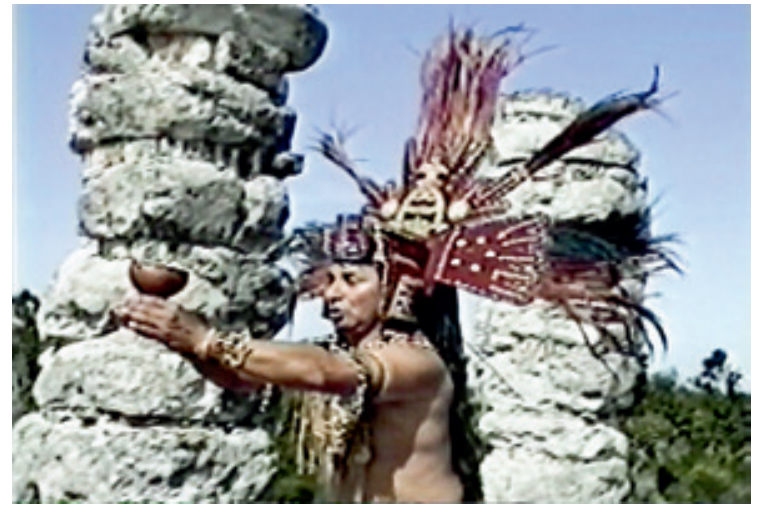

Jaime Aké, ofrenda a los Yuum Tsiles (1992), foto: Colectivo de Video Latino Midwest-Mérida para la series Rock the Boat, Nueva York: Deep Dish TV. Videografía: Raúl Moarquech Ferrera-Balanquet.

diferentes ángulos, posiciones y niveles. A veces inclinada, otras veces arrodillada sobre el lienzo, otras veces de pie, siempre moviéndose alrededor de la tela. Los olores emanaban de la pintura y llegaban a nosotros acentuando el sentir. Después continuaban su rumbo hasta todos los rincones de la sala. Y del lienzo emergía una cosmografía, como si desde sus manos, las semillas y los movimientos emanaran el mensaje que indicaba hacia donde debería lanzar el oloroso aceite de semilla. $Y$ así la creadora Inga, trazaba una cosmografía que me recordó las wiwas aparecer y desaparecer en los rumbos del firmamento anunciando los ciclos de la agricultura, de la cosecha, de la fertilidad, del goce de sentipensar la energía cósmica mientras esta trazaba geometrías variables muy distante del imaginario colonial cartesiano. Después de repetir los ciclos de plasmar los colores aromáticos como gestos sagrados y rituales, Rosa sentipensó el momento de detenerse y observó la creación desde diferentes ángulos. El olor del aceite de semilla arrayán ahora era más profundo. Con la ayuda de los museógrafos, la creadora colgó el lienzo en la pared de la Sala de Exposiciones ASAB.

Es la transformación del tiempo que se encarga de apropiarse y de construir algo más sutil, de cambiar las formas. Los pigmentos en un lienzo, generan su propia vida, adecuándose en él, tejiendo vida y construyendo su propio color, como la vida misma envuelta en un todo, su calidez, su sencillez y su conocimiento. (Comentó Rosa, cuando me acerque a felicitarla)

\section{Sonoridades, otra interconexión ancestral}

La relación de poder generada por la colonialidad sonora se configura en herramientas e instrumentos de dominio y control identificados en la imposición del lenguaje, el uso de los perros para la matanza de indígenas y las armas con pólvora que fueron prácticas que alteraron el sistema sonoro caribe, existente antes de la conquista: "se establece todo un sistemas de violencia a través de prácticas coloniales, mediante las cuales se generan actos sonoros que anuncian la muerte y el exterminio" (Estévez, 2012). El sentir auditivo indígena y afro ha sido intervenido por las políticas raciales y etnocéntricas de la modernidad/colonialidad, las cuales invisibilizan e intentan obstaculizar los procesos cognitivos y de subjetivización que se nutren de la sonoridad.

Junto a varios compañeros yucatecos miembros del Colectivo de Video Latino Midwest-Mérida (Ferrera-Balanquet, 1991) me encontraba en la ciudad maya de Aké, a 20 millas al este de Jo'. ${ }^{5}$ Realizábamos la grabación de unas escenas de Resistencia, video producido para la serie Rock the Boat, ${ }^{6}$ organizada por Deep Dish TV (1992) con la intención de contrarrestar la celebración colonial de los 500 años de la invasión europea a Abya Yala. Jaime Aké, integrante del colectivo, oriundo de la legendaria ciudad y heredero de la sensitividad y la cosmovisión maya yucateca, facilitó el permiso para filmar en el territorio custodiado por los habitantes del pueblo desde que dejó de funcionar

\footnotetext{
5 Jo' es el nombre maya yucateca de lo que hoy se conoce como Mérida. Los maya hablantes aún recuerda que sus ancestros Ilamaban Ich Caan Si'ho, nacidos dentro del ojo del cielo, a la ciudad maya antes de la colonización y en la actualidad se refieren a ella como Jo'. Es común escuchar en los pueblos aledaños Tan in bin Jo, estoy dirigiéndome a Mérida.

6 Rock the Boat fue una serie de programas producidos por activistas mediáticos y coordinada por la activista puertorriqueña Ivette Nieves-Cruz en 1992 para Deep Dish TV, el primer network satelital de base comunitaria con sede en la ciudad de Nueva York. Resistencia Latinoamericana, fue un programa de 58 minutos que coordiné con varixs videostxs y colectivos independientes de Latinoamérica, entre ellos el kuna panameño, Cheche Martínez, quien relacionó los efectos de la invasión colonial española y de la invasión norteamericana sobre los indígenas panameños.
} 
la hacienda y plantación de henequén construida junto a los edificios mayas durante la colonia.

Jaime vestía un taparrabo y en su cabeza un penacho que utilizaba en sus danzas rituales. Desde la cima de la pirámide me preguntó si la cámara de video capturaba sus palabras y sorprendido por la distancia y la nitidez de la voz de Aké, comenté mi asombró. Jaime relató que la pirámide había sido concebida arquitectónicamente para que el sonido de la palabra viajara desde la cima hasta su base pues a través de la voz se transmitía la lectura e interpretación que los meen'o'ob, los chamanes mayas, realizaban de los códices durante las ceremonias y los rituales.

Mientras yo vivía en una época en la cual la reproductibilidad sonora sólo podía expresarse a través de complicadas máquinas atadas al sistema info-eléctrico activado por la explotación de hidrocarburos, los mayas yucatecos, desde muchos siglos antes de la conquista inconclusa, desarrollaron un sistema de transmisión sonora gracias a su entendimiento de la relación entre la construcción arquitectónica, la naturaleza y las fuerzas cósmicas. No había comprendido que:

La generación sonora pensada desde las particularidades de las historias coloniales puede contribuir a decolonizar la visión dominante del arte que posiciona, por un lado el sonido como uno de sus elementos innovativos, y por otro, a la condición colonial desde la cual se genera el discurso artístico (Estévez, 2012, p.58)

Reconocer la importancia del sonido en el imaginario decolonial, conlleva discursar sobre como sentir y pensar la sonoridad y el ritmo del lenguaje son claves importantes en nuestra producción creativa insurgente, pues desde la opción decolonial nos resulta urgente "indagar en las relaciones de poder que estructuran a lo sonoro como un régimen

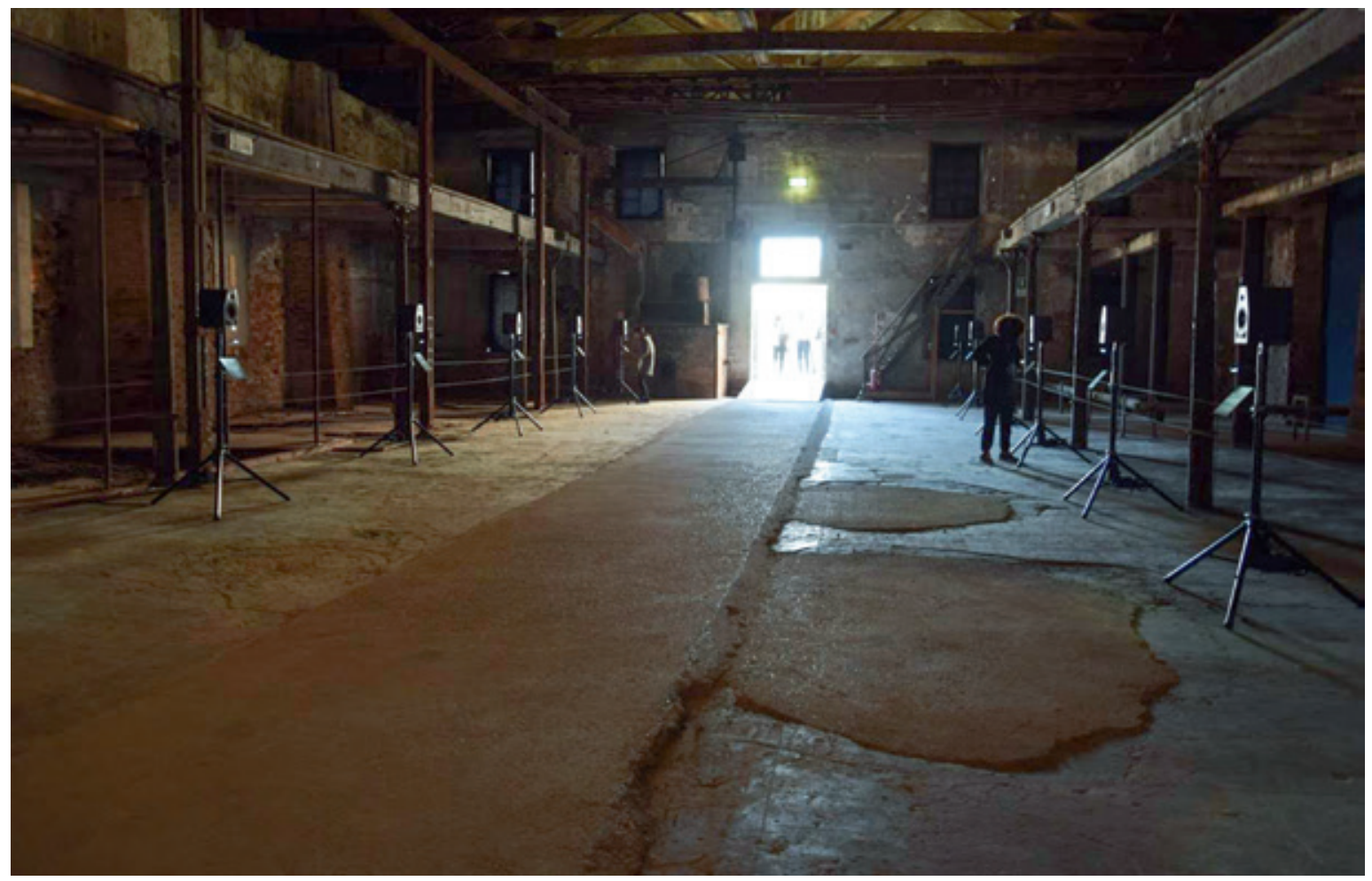

Rokeb' iq' (2015). Instalación sonora de Sandra Monterroso, en "voces indígenas". 56 Bienal de Venecia. Fotografía: cortesía de Sandra Monterroso. 


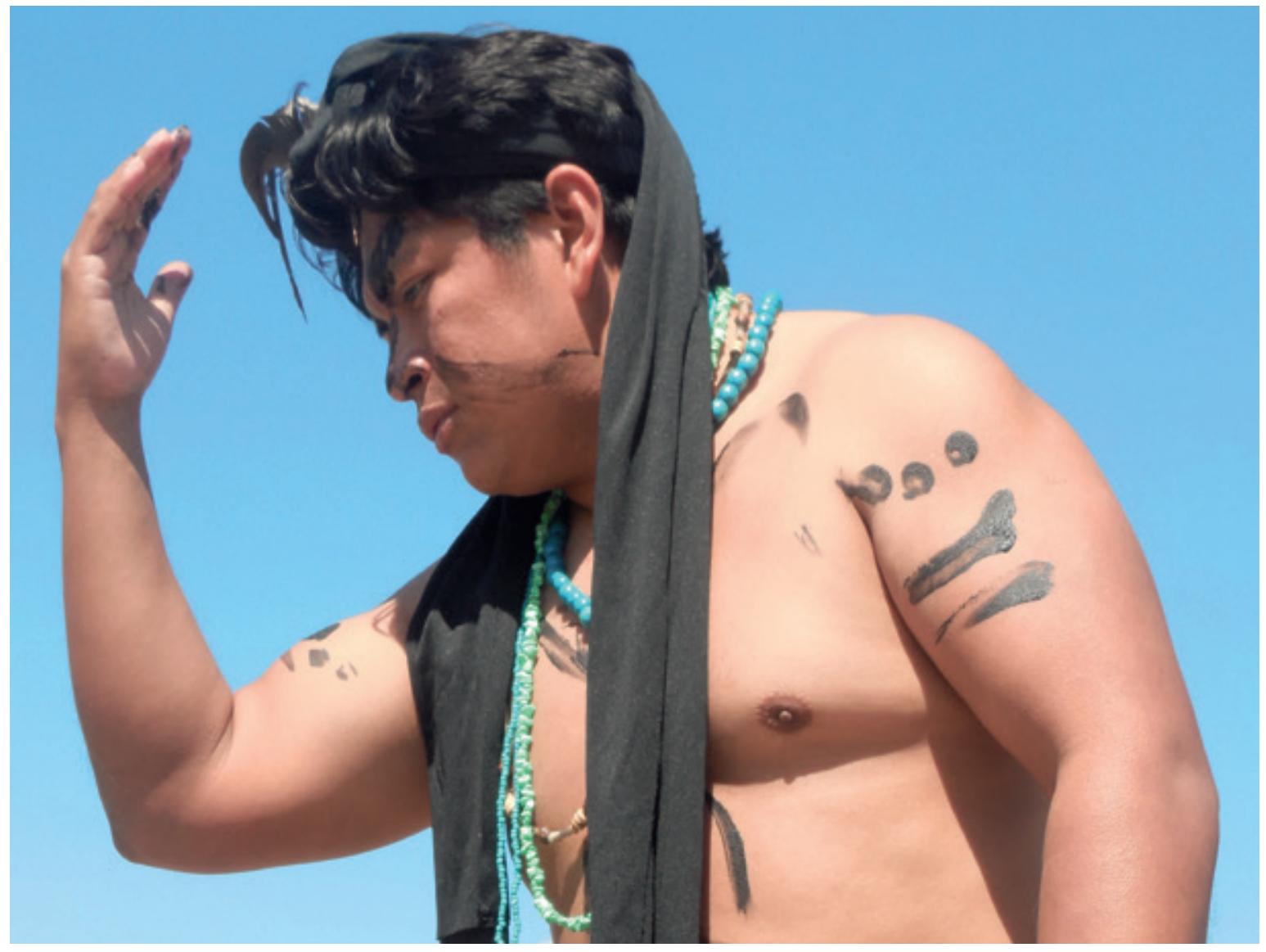

Ui (2014-2015), ceremonia performance de Isaac Esaú Carrillo Can. Fotografía: Raúl Moarquech Ferrera-Balanquet.

histórico dominante de la violencia colonial" (Estévez, 2012, p. 61). Imaginar una sonoridad otra, enunciada a partir de ritmos y temporalidades que fluyen con la producción inmediata de las historias orales es ubicar los referentes locales, sociales e históricos en relación con el sonido como territorio de lucha. La forma sonora de expresar el lenguaje loko, kairibe, al igual que el maya yucateco, está altamente relacionado con la forma en que Ixs sujetxs, la tribu y/o la comunidad relatan la historia en ese momento. Esto lo podemos constatar en los ritmos acústicos que emergen con el llamar y responder, las repeticiones en los relatos, los tonos y volúmenes asociados con el flujo cósmico y el sonar del viento.

La artista maya k'iche, Sandra Monterroso, ha creado una serie de proyectos relacionados con la vida sensitiva Maya. Rokeb' iq' (2015) decoloniza el sentir sonoro al incorporar voces y sonoridades ancestrales mayas en una experiencia sensorial que promueve la expresión creativa y el pensamiento crítico decolonial de la artista. La pieza argumenta la política de expresión cultural desde ser mujer, maya, creadora que realza la palabra, la sonoridad en un gesto creativo insurgente decolonial. En un intercambio electrónico, ${ }^{7}$ Monterroso expresa:

La obra está escrita en maya Q'qchi por mí... intento, dar esa misma sonoridad pero también mezclado con temas contemporáneos insertos en esas mismas metáforas. Está escrito en la forma en la que nuestros antepasados contaban historias y arte sagrado. Proporciona un conocimiento "otro" por escrito. El trabajo de sonido se lleva a cabo de manera performativa también realizado y grabado con la voz y los sonidos de mi propio

7 Este intercambio electrónico se llevó a cabo entre abril y octubre de 2015 


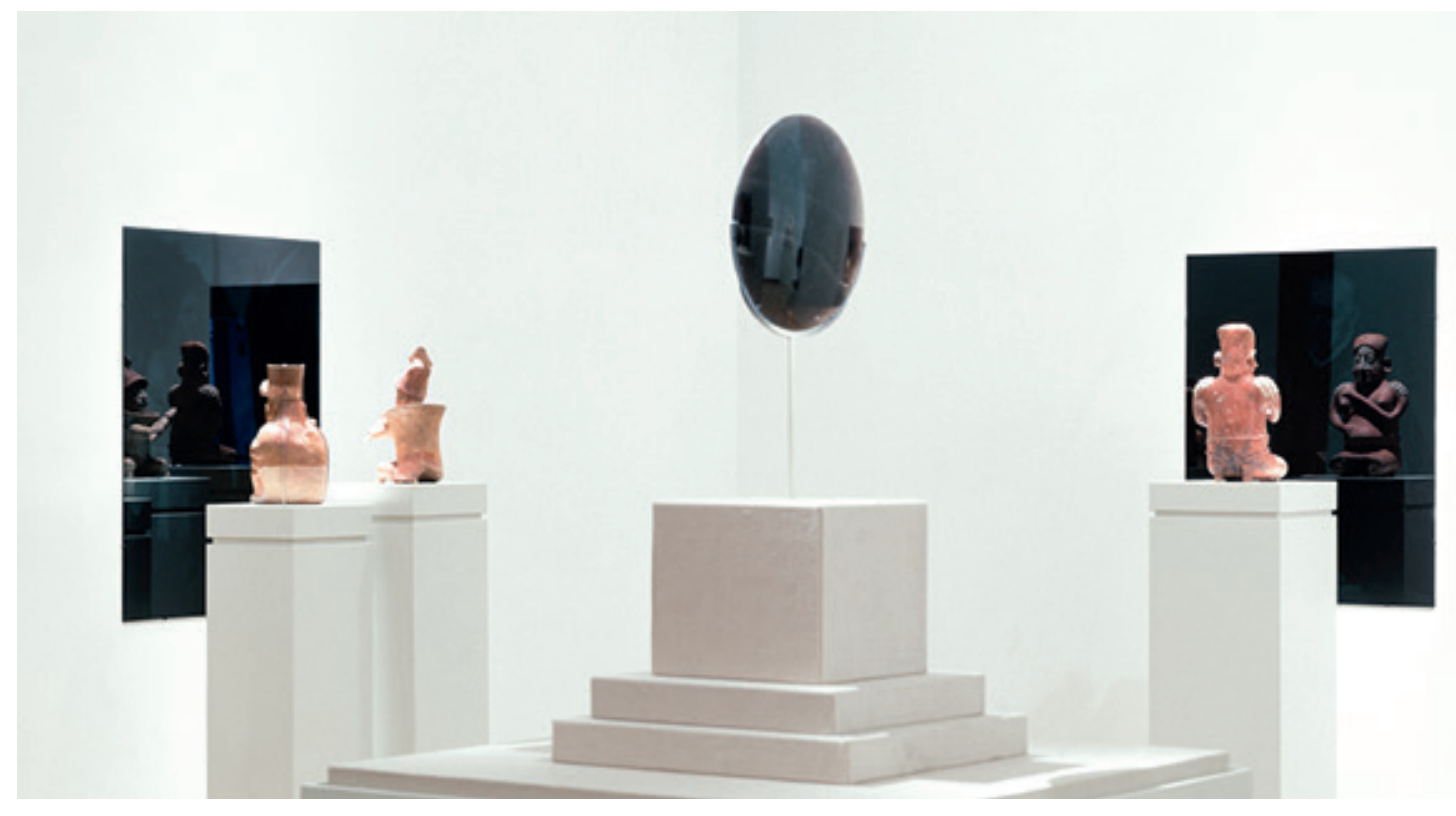

Espejo Negro (2010), Instalación de Pedro Lasch, Centro de Escultura Nasher. Fotografía: cortesía de Pedro Lasch.

cuerpo. Lo que hace que el sonido que tenga diferentes niveles Este trabajo hace un llamado a una geopoética del ser desde un pensamiento decolonial. En este caso la pieza se vuelve una obra en proceso ya que deberá traducirse del Maya Q'eqchi' al idioma del lugar donde se exhiba. (Monterroso, 2015)

A pesar de la naturalización del lenguaje español en muchos territorios de Noj Kairibe, una de las formas en que se mantiene la sonoridad ancestral es a través de Ixs abuelxs quienes continúan la producción de conocimientos y sonidos como la palabra que es sagrada y se debe pensar antes de ser pronunciada permitiendo "rastrear prácticas sonoras-culturales cuya co-existencia y trayectoria revelan un contorno, un momento o camino a la decolonialidad" (Estévez Trujillo, 2012). En el performance Ui (2014-2015) del escritor y artista interdisciplinario maya yucateco Isaac Esaú Carrillo Can, la sonoridad de la lengua maya proporciona la fuerza vital que lo impulsa a despojarse de la modernidad en un desvestir de ropas europeas para luego reinscribir la pintura corporal y la vestimenta maya clásica. $U i$, en maya tiene dos significados: Luna y collar o pechera, en el maya antiguo la raíz de la palabra también era usada como adjetivo posesivo de la tercera persona (Leti') la cual es una palabra por naturaleza andrógina y difumina la separación que existe entre el hombre y la mujer. Uj nos muestra la capacidad para desligarnos del patrón moderno colonial y sentir, pensar, crear y expresar desde los conocimientos ancestrales y de la vida social de nuestras tribus y comunidades.

\section{Miradas transversales, táctil, distancia olfativa}

El proyecto Espejo Negro (2010) de Pedro Lasch, traza relaciones simultáneas a situaciones históricas, distantes, pero entrelazadas por la colonialidad: las rutas mesoamericanas del mercado de espejos de obsidiana y de pirita (Thompson, 1970, p. 183), en los años previos a la invasión europea y la obsesión antropológica colonial por coleccionar libros, códices, artefactos, esculturas y textiles en los museos occidentales. Lasch, retoma el uso de los espejos de obsidiana empleados en las prácticas espirituales de la cultura náhuatl y la relación de estos con la deidad Tezcatlipoca, quien era conocida con el apodo de Espejo Humeante. Lasch, asegura haberse dirigido a los sótanos del museo Nasher sin tener una idea clara de cómo iba 
a diseñar la exposición, su encuentro con el espejo de obsidiana y la relación de éste con la forma de vida y pensamiento mesoamericano le sirvió para navegar, sentir y expresar los conceptos que enmarcaron el proyecto. ${ }^{8}$ El significado del nombre de Tezcatlipoca, Espejo Humante, enuncia una serie de conceptos náhuatles que desmantelan la lógica binaria moderna. Su ser en constante movimiento cósmico, transformado en masculino y femenino, de acuerdo a la imaginación espiritual náhuatl, condujeron al artista a escoger el resto de las piezas que incluiría en la instalación cuyos materiales varían desde roca volcánica hasta cerámica pintada con diversas mezclas.

En la cultura material mesoamericana, la obsidiana traza importantes rutas culturales y económicas originarias de Xilotepeque, El Chayal e Ixtepeque (Golitko et al, 2012) en el sur de los que hoy es Guatemala, llegan a puertos como la bahía de Chetumal y desde allí bordean la península de Yucatán para llegar a Veracruz donde entran a tierra y siguen hasta el centro de México. Me atrevo a decir que estas rutas del comercio de obsidiana, junto a la variabilidad de Tezcatlipoca, inspiraron a Lasch para trazar las diferentes rutas que pueden tomar Ixs visitantes cuando se encuentran en el interior de la instalación.

Contrario a la cronología lineal que imponen las curadurías en los museos con el fin de acelerar el paso de los visitantes, Espejo Negro (2010), demanda rutas alternativas que permiten el diálogo sensorial conceptual propuesto por el creador. La sala del museo tiene cuatro entradas y dependiendo de la que escoja el visitante, se articulará el andar a través del recinto. La variabilidad se encuentra en la disposición de las múltiples rutas posibles. Al final del catálogo impreso se muestran una serie de suites, cuatro de ellas conforman las rutas planeadas por Lasch para desarrollar la serie fotográfica: Vista Posterior, Confrontación Escultura-Pintura, Espacial y Construcción Social

\footnotetext{
8 Conversaciones durante las secciones de Time and The Stolen Memory, un proyecto de investigación y debate organizado en Duke University en el otoño de 2011 y extendido hasta 2013. Entre las actividades de este grupo de trabajo se incluye conferencias, paneles y publicaciones colectivas. La presentación del panel Estéticas Decoloniales en la Bienal de La Habana de 2012, fue parte de este proyecto.
}

(Lasch, 2010). En esas múltiples posibilidades para navegar la sala, Lasch comienza a dialogar sensorialmente con el tacto antes que con la vista, pues al tener que escoger como desplazarse por las rutas, la movilidad también acciona el pensar. El creador propone una acción participativa, que ocurre tanto a nivel corpóreo, sensorial y en el imaginario de Ixs visitantes.

Existen dos espejos: uno inscrito en el objeto mesoamericano y una series de espejos que el creador ha elaborado con vidrio oscuro y la imagen impresa de fragmentos de pinturas coloniales (Lasch, 2010). Estos últimos están colocados en las paredes de la sala; los objetos y esculturas encontradas en el sótano están sobre pedestales confrontando a los espejos y de espalda a los visitantes. La posición de las esculturas mesoamericanas también muestra el gesto radical que desliga el proyecto de los parámetros museísticos occidentales y de la mirada cartesiana construida ópticamente hacia un centro de convergencia. Cuando el visitante se acerca a la espalda de la escultura ocurre una construcción geométrica visual donde se interpela el sentir y el pensar como gestos decoloniales. Cuando se reconoce que los espejos contienen en el fondo fragmentos de pinturas coloniales, simultáneamente se reconoce que las esculturas y objetos mesoamericanos están mirando hacia esos fragmentos y hacia el reflejo de ellos mismo. La simultaneidad nos remontan a tiempos otros no cronológicos y por ende se efectúa un desenganche de la progresión moderna eurocentrada.

La geometría variable visual que Espejo Negro propone amplificar, es el intercambio de miradas en temporalidades múltiples, cuando el visitante reconoce su visión, la de la estatua mesoamericana y la observación colonial implícitas en los ready-mades de pinturas colocadas al fondo de los espejos oscuros. Al activar el poder de la mirada hacía las esculturas mesoamericanas, Lasch articula un acto de ver/sentir desde el territorio y la memoria ancestral de Mesoamérica donde el entrecruce de miradas instiga a reconfigurar la ideología visual eurocentrada y el condicionamiento social al punto de fuga de la perspectiva central realista óptica. En el reconocimiento del entrecruce, la encrucijada de percepciones visuales y temporales, se localiza otro de los gestos decoloniales que desligan a Espejo Negro de los parámetros estéticos eurocentrados. 
Aquí no existe reproducción mecánica, pero se manifiestan proyecciones simultáneas que entretejen la geometría cósmica inscrita en el imaginario náhuatl de Tezcatlipoca. El humo del espejo viaja con el viento $l k$, y el viento Anahau a otras latitudes.

\section{Las aguas sagradas de La Llorona sanan la Natura}

En el mural Las Aguas Sagradas de La Llorona (2004) de la creadora chicana Juana Alicia Araiza, el ts'aak, la sanación decolonial se manifiesta al ubicar la obra en el espacio público. Aquí es en donde se activa el ts'aak comunitario, a través de una conversación social, entretejiendo problemáticas presentes con la memoria ancestral mesoamericana. Este proyecto fue realizado en las paredes de un edificio de dos plantas ubicado en el Distrito La Misión de San Francisco, un área habitada en su mayoría por chicanos e inmigrantes centroamericanos.
El muralismo chicano conecta su historia insurgente con su contraparte mexicana de principios de siglo XX, el cual intentaba retomar las dimensiones mesoamericanas y transportarlas a la vida social de México. El muralismo mexicano sirvió de camuflaje a la política clasista y multicultural de Vasconcelos cuando era ministro de educación y se desarroIló, en su mayoría en los interiores de edificios de oficinas estatales. No podemos obviar el intento por re-imaginar la vida sensitiva mesoamericana en las soluciones dimensionales, volumen, colores y movimientos de este periodo que luego le sirvieron a Ixs creadores xicanxs para re-imaginar a Aztlán en la calles de muchos barrios del suroeste de Estados Unidos. Cuando las artistas chicanas imaginan, sienten, piensan y realizan un mural, ellas enuncian una protesta en la cual reconocemos una denuncia social de la violencia de la matriz colonial hacia Ixs campesinxs, los indígenas, las mujeres, la tierra y la naturaleza. (Robles, 1989)

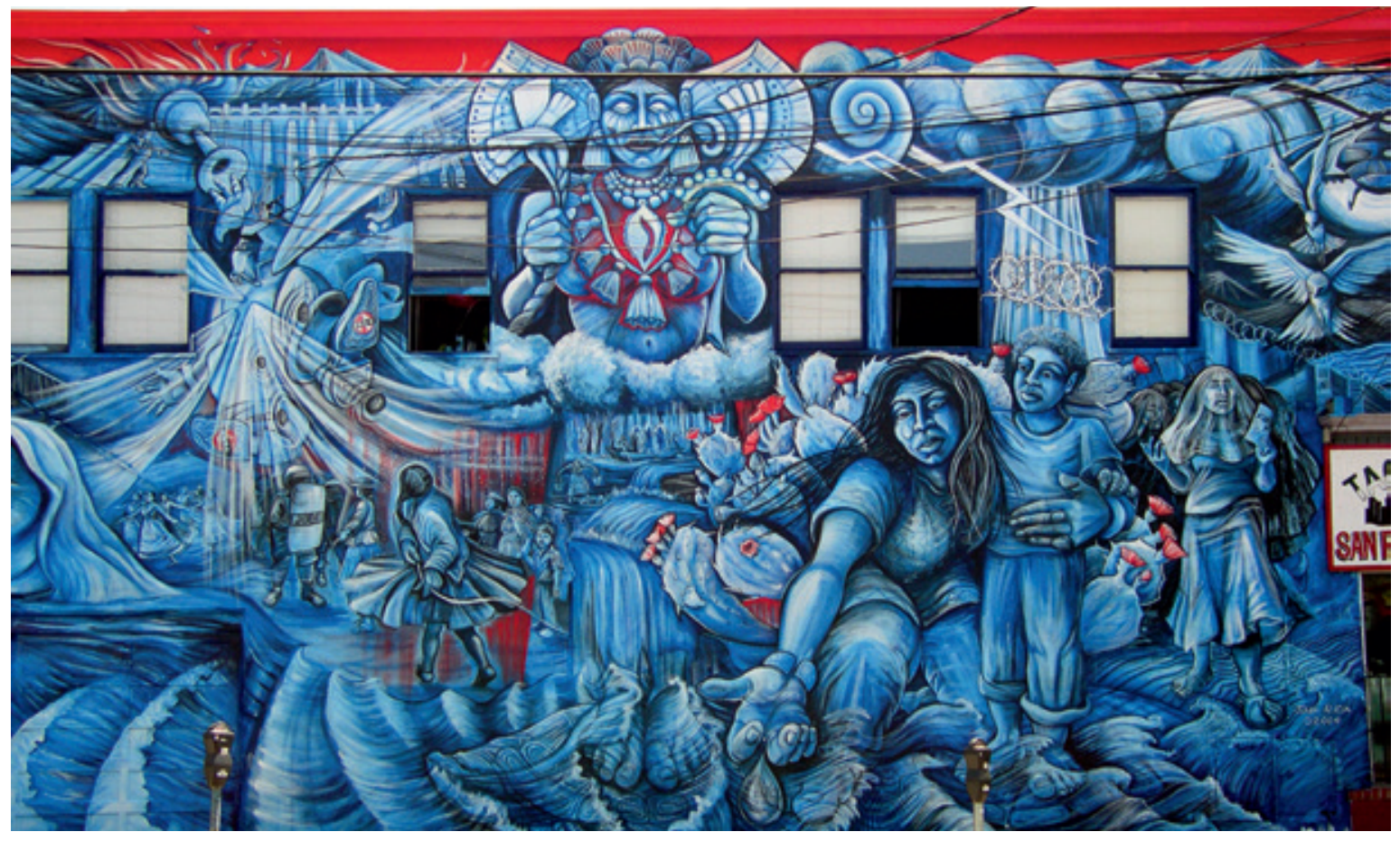

Las Aguas Sagradas de La Llorona (2004), mural de Juana Alicia Araiza. Fotografía: cortesía de Juana Alicia Araiza. 
Descendiente interétnica de una familia chicana y judía rusa del sur de Estados Unidos, Juana Alicia reconoce que su muralismo es un acto de protesta y un testamento que entreteje el sentir visual de la audiencia con el tacto a través de un gesto interpretativo y el movimiento corporal. En una entrevista publicada en la revista electrónica Apuntes, la creadora afirma:

...Me siento como una bruja... tengo una visión y junto mis ideas, la información, los sueños, la literatura que me inspira, experiencia de la calle y trato de teierlas para alcanzar esa visión... para presentar una narración visual de nuestras preocupaciones por la contaminación ambiental, el estatus de la mujer, la inmigración, los derechos humanos... pero también el hacer el trabajo me satisface a nivel sensorial... (Araiza, 2013).

En Las Aguas Sagrada de la Llorona (2004), Juana Alicia traza su relación con los murales mayas de Bonampak cuando emplea el uso del azul maya para desplegar un relato visual que está muy lejos de suscitar el acto contemplativo predominante en la visualidad estética moderna. Las Aguas Sagradas de La Llorona (2004) requiere de una activación del movimiento corporal para su interpretación. Al sentirnos atraídos hacia la monumentalidad pictórica se ejecuta una inmersión en la obra, siendo esta una de las dimensiones que algunos creadores decoloniales latinxs utilizamos para desengancharnos del acto contemplativo renacentista kantiano. La política de la locación, del espacio público, junto al empoderamiento comunitario y el activismo ecológico son temas que re-emergen en varios de los murales de la artista chicana:

...sus preocupaciones con las formas en que los cuerpos generizados y racializados ocupan el espacio público y social... [Al] reflejar el sentir emocional y espiritual como parte del paisaje público...el flujo visualizado de la energía y la identidad entre personas y objetos (Pérez, 2007).

Juana Alicia decide narrar a través de escenas trazadas en diferentes regiones de la obra. La inmediatez del sentir visual conlleva la necesidad de activar su lectura en un movimiento que dinamiza la corporalidad política comunitaria: necesitamos movernos hacia, a través y desde el mural para interpretar la globalidad de la narración visual imaginada por la creadora. La mirada sigue las líneas, volúmenes, formas, tonos. Nos sentimos instigados a desplazarnos para activar el acto cognitivo de re-crear el relato visual con respuestas sensoriales, físicas y emocionales.

Mucha de la composición se desenvuelve alrededor de la figura de Chalchiuhtlicue, la deidad mexica de los lagos y Ios arroyos quien muchas veces es dibujada en el imaginario mesoamericano vistiendo una saya de jade, como en la escultura monumental Teotihuacana (...) En el mural de Juana Alicia, ella también viste la saya de jade, pero la suya se convierte en una serie de cascadas de agua y torrentes que irrigan las tierras alrededor de ella (....) Chalchiuhtlicue [en el mural] está llorando frente a escenas de injusticias sociales y violencia que suceden alrededor de ella, como sucede en el rollo de voces que emana de su voz, implicando que ella habla en contra de esas condiciones sociales (Latorre, 2008)

La paleta azul empleada por Juana Alicia en el mural, evoca las noches de Ui, luna en el Mayab y el andar por los caminos de Xilbalba, donde la incertidumbre de la noche se refleja en el correr de las corrientes subterráneas de los cenotes. Todo parece estar en movimiento como las fuerzas cósmicas: el movimiento del agua; del gesto de la mujer arrodillada que sostiene al hijo con una mano y con la otra toca el agua; la multitud de mujeres que avanza hacia el plano frontal; el helicóptero en una esquina y los caracoles espirales a cada costado de Chalchiuhtlicue que nos informan del rompimiento con la imagen estática moderna. La conciencia ecológica que narra el mural se encuentra conectada con la memoria ancestral mesoamericana, el tiempo de la agricultura y la fertilidad, y con situaciones específicas latinoamericanas como la contaminación de los ríos, los lagos y la privatización del agua, como sucedió en Bolivia durante la llamada Guerra por el Agua, en octubre del 2003 (Gente y Ruiz, 2008). La narración visual y la necesidad de inmiscuirnos corporalmente en el mural son gestos creativos políticos comunitarios que la artista chicana reconfigura en relación a las prácticas creativas y a las ts'aak, las curaciones ancestrales indígenas ahora re-imaginadas en un devenir chicanx y desplegadas en la calles del barrio latino para activar el desenganche de la colonialidad, la ts'aak tribal. 


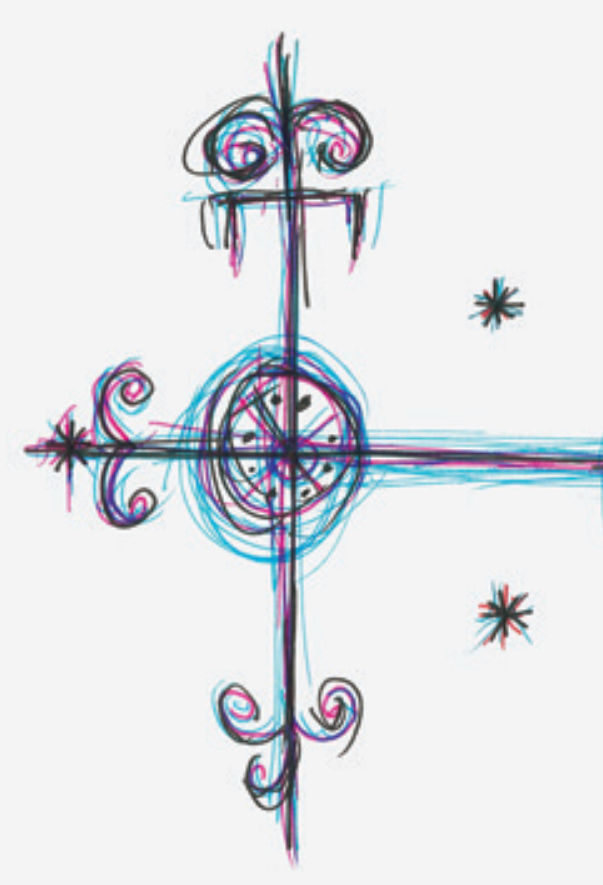

Marasa Dosau Dosha

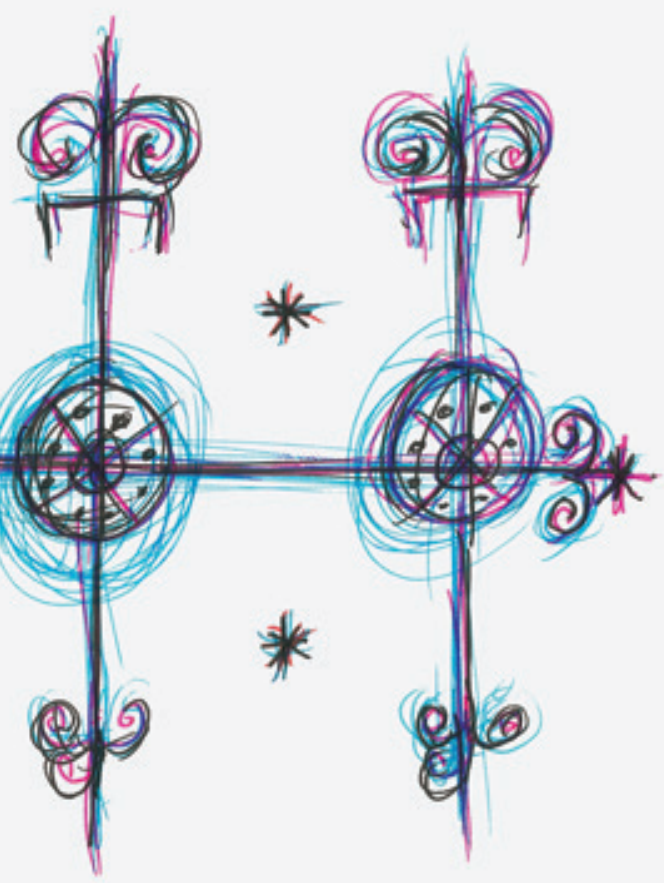

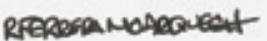

Marasa Dosa Dosua, de la serie Mariposa Ancestral Memory. ( Raúl Moarquech Ferrera-Balanquet, 2013-2015). Dibujo, tinta sobre papel.

\section{Sabiduría, memoria, espíritu ancestral: Cimarronaje creativo insurgente}

Reconectar con la sabiduría, la memoria ancestral y los ancestrxs a través de una navegación crítica insurgente entrelaza el aprendizaje con el re-surgir de conocimientos otros de Ixs abuelxs kairibexeri, kongo, lukumi y yorubas. Como afirma el artista y pensador afro colombiano Albán Achinte: “...los procesos de re-vitalización de la memoria colectiva de muchos de nuestros pueblos originarios y afro descendientes caminan por una senda distinta a asumir el pasado como un mero acto de recordación..." (Albán, 2009). La memoria ancestral está intrínsecamente entretejida con la memoria política para desde esa encrucijada hacer posible el relato de las historias orgánicas, agenciar el conocimiento y los saberes ancestrales y re-surgir la memoria subjetiva en relación con formas y temporalidades otras de acercarnos a la experiencia de vida de nuestras comunidades. La relación ancestral, entendida a través de la Poética de la relación, propone una interconexión fluida y variable entre la naturaleza, la cultura, el cuerpo, la mente, la memoria, lo animal, lo cósmico, la memoria colectiva y la expresión social que emerge a partir del desconcierto que provocó el desplazamiento y la desterritorialización impuestos por la esclavitud. (Glissant, 1997)

Regresaba a La Habana desde Berlín donde participé en BE.BOP, ${ }^{9}$ con Memoria Mariposa Ancestral, un proyecto interdisciplinario compuesto por un performance multimediático, una instalación y proyecciones de imágenes audiovisuales. Había realizado una profunda investigación sobre las formas en que la modernidad/colonialidad niega las escrituras otras activas en Noj Kairibe y me enfoqué en las escrituras afro descendientes Vèvé, Anafourana y Palo Monte-Kongo en Cuba y Haití

9 BE.BOP, es organizado por la curadora y escritora decoIonial Alanna Lockwood desde 2012 en Berlín, Alemania. 
(Ferrera-Balanquet, 2014), las cuales me condujeron a entender la temporalidades simultáneas en los imaginarios indígenas y afro descendientes que habitan Noi Kairibe y a la presencia de deidades andróginas en la espiritualidad kairibe como Attabeira y en los panteones Rada, Yoruba y Lukumi como Oloddumare, Obatala, Oddudua, Ochumare/ Damballa, Weddo, Olokun/La Sirene/Agwe, Inle, y Shango/lbeyis/Marasa Dosa Dosua (FerreraBalanquet, 2013). En esta encrucijada, logré entender los mecanismos religiosos de la matriz moderna/colonial para mantener su hegemonía normativa, heterosexista, patriarcal, eurocristiana sobre el erótico kairibe al no permitir el acceso a los relatos de creación indígenas y afro.

Un amigo de la adolescencia, afro descendiente, me invitó a un espectáculo del ballet folklórico nacional en el teatro Mella de La Habana. Oprimido por la representación heteronormativa de Yemaya Olokún, comenté mi desilusión. Todos Ixs iniciadxs en Yemaya Olokún cuando agenciamos la relación ancestral a través de rituales y ceremonias en las cuales nos identificarnos como hijxs de Ix Oricha vestimos faldas y pañuelos, no importa la preferencia sexual. Que el coreógrafo dividiera la escena en [hombres] y [mujeres] y, a través del vestuario, representara la colonialidad de género, era una forma muy sutil de ejercer el heteropatriarcado. -Es una historia de amor- respondió mi amigo. [Amor] es un afecto heterenormativo. Solo los patriarcas pueden darse el lujo de articular una sensación de felicidad ficticia proyectada en el matrimonio legislado y la reproducción biológica. ¿Por qué no se puede imaginar una historia de [amor] entre una [mujer] y un [hombre], hijos de Yemaya, donde ambos visten faldas en honor a la Oricha? -Pensarían que es una relación lésbica- argumentó mi buen amigo y de pronto, enojado, me acusó de traer ideas imperialistas.

Las tradiciones y el folklore también son mecanismos de la matriz moderna/colonial. La tradición y el folklore son prácticas que mimetizan el poder en las formas de representación parciales cuando reproducen los patrones, en este caso, heteronormativos. La representación parcial sugiere que hay algo afro en el espectáculo folklórico empleando la música, algunos gesto corporales y objetos, pero el poder, la mirada y el pensar colonial están presentes en la heteronormatividad, que bloquea tanto el acceso a la memoria ancestral, como la necesidad que tiene los afrodescendientes de que la "representación" sea un catalizador del proceso radical liberatorio. A través de la tradición y el folklore, el estado nación rearticula su noción de identidad multicultural y aparenta su democracia porque la identidad del otro sigue mediada por la colonialidad del poder y del saber. El estado moderno/colonial permite la presencia de la tradición y el folklore porque mimetiza tanto la estructura de poder, como la ancestralidad que (al ser mimetizada) cosifica su capacidad para decolonizar vaciada en la repetición de estructuras coloniales, en este caso heteronormativas patriarcales. La representación folklórica se encuentra entre líneas, es aparentemente étnica, pero no es la memoria ancestral afrodescendiente. Se localiza en un lugar intermedio parecido a donde se encuentra la diferencia colonial. El caso aquí es que la visualidad, gesticulación y sonoridad aparentan la diferencia y si no localizamos el análisis desde la memoria ancestral para entender cómo la apariencia es enmarcada por los patrones de poder, la colonialidad del ser puede reinscribirse en los sujetos afro descendientes que presencian el espectáculo folklórico. Bhaba (2002), asegura que esto "son los efectos de una negación que niega la diferencia del otro (...)".

Para el artista decolonial, el cimarronaje ofrece la oportunidad de trabajar con múltiples gramáticas conceptuales e imaginarios que no pueden ser accedidos por la lógica colonial, a pesar de que en la superficie empleamos elementos visuales de la geometría euclidiana. La obra imbrica significados otros que al conjugarse con la apariencia denotan la variabilidad del acto cimarrón gestado en el empleo de geometrías ancestrales indígenas, africanas, árabes, canarias que complejiza la expresión creativa. El cimarronaje decolonial se encuentra entrecruzado con la identidad, el género, la clase, la materialidad, lo erótico, la sexualidad, espiritualidad y la relación cosmos-natura.

La historiografía colonial perpetúa la idea de la esclavitud como un hecho finito gracias a la abolición y las guerras de independencia, la cuales reinscribieron la colonialidad que todavía ejerce sus opresiones: racismo, homofobia, sexismo, clasismo a través de individuos e instituciones. Aún estamos imbricados en el aparato colonial y muchas veces estamos forzados a ejecutar el acto cimarrón para desengancharnos. "El cimarronaje... es una actitud 


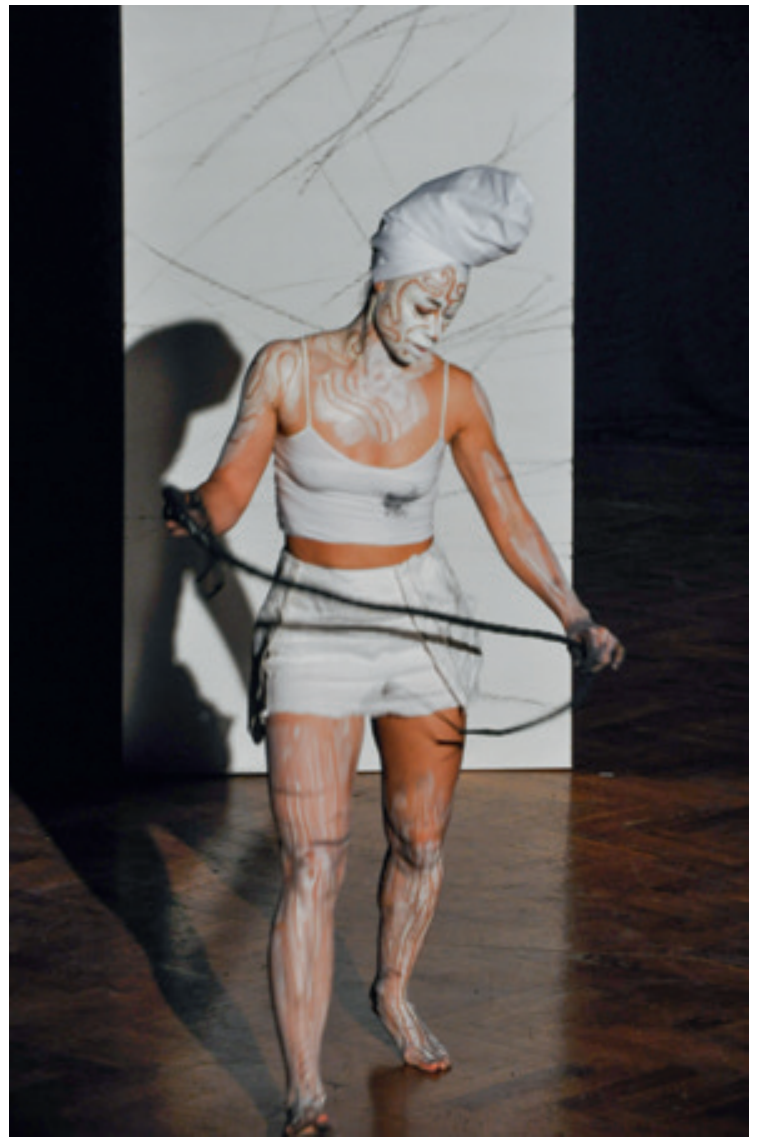

Whip It Good (2013), performance e interacción social de Jeannette Ehlers, BE.BOP 2013. Fotografía: Wagner Carvalho.

ante la vida, un modo de actuar, una condición para existir, una cualidad que se transpira en el comportamiento y la supervivencia cotidiana de nuestros pueblos caribeños." (Muñiz, 2007)

La experiencia cimarrona kairibe, es un territorio extendido que atraviesa la vida social de la artista danesa trinitobaguenses Jeannette Ehlers y la impulsa a romper con las estructuras coloniales que predominan en el arte moderno. Su performance Whip It Good, fue incluido en BE.BOP 2013, una curaduría organizada por Alanna Lockward, en Berlín, a la que fui invitado. Frente a la incertidumbre de la audiencia, presenciamos un lienzo rectangular enyesado que colgaba del techo y un sombrero en el piso, a unos metros frente al lienzo. Minutos después apareció la artista con un látigo en la mano y vistiendo telas blancas alrededor de su cuerpo y su cabeza; mostraba pinturas tribales en partes del cuerpo y su cara. Jeannette, se acercó al sombrero e introdujo su mano extrayendo residuos de polvo de carbón que luego esparció por el látigo. Cuando sintió que este tenía suficiente carbón, se paró, caminó hasta el lienzo y comenzó a dar latigazos sobre el blanco enyesado. En aquel instante, mi lectura ágilmente cruzó siglos de esclavitud y regresó para nombrar la esclavitud cognitiva que muchxs experimentamxs en las escuelas de arte modernas cuando se nos obliga a pintar en el rectángulo y representar el realismo cartesiano. La artista danesa trinitobaguense, reconfiguraba la historia colonial de la pintura y su objetualidad desde la pintura tribal en su cuerpo hasta los gestos repetitivos que dejaban marcados los latigazos sobre el lienzo que, en mi lectura, documentaba los tratos [inhumanos] a que fueron sometidos Ixs esclavxs indígenas, afrciacnxs y asiáticxs en las plantaciones caribeñas.

Cuando la artista invitó a la audiencia, no tuve reparos en formar parte del grupo que avanzó a la acción comunitaria. Jeannette untaba el polvo del carbón en el látigo y lo ofrecía a quien decidía participar. En el instante de la interacción social desmonté mis miedos sobre aquel lienzo inscribiendo la historia de violencia junto a los trazos de Ixs otrxs participantes. La artista logró transformar un cimarronaje cultural individual en un cimarronaje en cuadrilla donde muchos sanamos heridas coloniales inscritas en territorios profundos inconscientes donde la creatividad, la memoria y los Ikus, muertos, salieron a expresar el gesto de desenganche.

Estrategias creativas cómo la capacidad para sentirse en conexión con el cosmos-natura, la inclusión de movimientos asimétricos; el sonido de los tambores; el uso de llamada y respuesta como ritmo; la habilidad para insertarnos en el mundo mágico hiperreal; el empleo de tiempos simultáneos; el uso de geometrías variables cósmicas que invalidan la linealidad cronológica; el crear ceremonias performativas donde la audiencia se convierte en la hacedora de la obra; el poder de nombrar las opresiones y la capacidad de sanar; reconectar la experiencia de vida con la memoria de los ancestros y el poder de los Orichas; desmontar la jerarquía [hombre] vs naturaleza; la ecología ambiental, entre otras, son estrategias cimarronas decoloniales que muchxs empleamos en nuestras expresiones insurgentes creativas. 
El cimarronaje cultural actualmente se da de formas variables de acuerdo a la experiencia de Ixs creadorxs y las estrategias conceptuales que emplean para indagar en la memoria ancestral, las formas en que se manifiesta la reformulación de la cultura popular, el reciclaje como gramática conectada a la conciencia ambiental, la re-imaginación de la ceremonias y rituales, la inclusión y participación de la audiencia en las obras, la resistencia frente a la exclusión de las plataformas del mercado de arte, la valorización de expresiones marginadas entre otras. (Muñiz, 2007)

En este proceso de reconfigurar el significado y la trascendencia del cimarronaje desde la opción decolonial, reconocemos que esta estrategia creativa insurgente se encuentra altamente relacionada con la identidad en política, el desmantelamiento del género como dicotomía sexual, el entendimiento de la diferencia entre materialidad y materialismo, el erotismo cósmico, la espiritualidad ancestral, las cosmovisiones de las culturas nativas e inmigrantes y nuestra ubicación en la relación cosmos-natura. Las acciones del cimarronaje creativo decolonial, se originan en el propio proceso de desafiar al poder hegemónico y la exclusión de nuestras sensorialidades. El cimarronaje decolonial reubica el proceso cognitivo y los saberes ancestrales para desmontar los estereotipos modernos coloniales y promover la interculturalidad, el diálogo intracultural y las subjetividades interétnicas. Al encontrar la posibilidad de re-imaginar desde nosotrxs mismxs y re-existir desprendidxs del eurocentrismo, el cimarronaje decolonial articula un entramado de saberes que agencia la creatividad radical insurgente en relación dialógica con la experiencia, la memoria ancestral, las situaciones sociales que experimentamos, la sabiduría de las comunidades desplazadas y la relación cosmos sujetx sentipensante - natura.

\section{Referencias}

Araiza, J. A. (octubre, 2013). "On Art, Activism, and Social Justice: An Interview with Juana Alicia", Apuntes: a Latino Journal, Disponible en: http://apuntesli.com/ on-art-activism-and-social-justice/

Albán Achinte, A. (Julio-diciembre, 2010). Comida y colonialidad. Tensiones entre el proyecto hegemónico moderno y las memorias del paladar. Calle14: revista de investigación en el campo del arte, 4(5), pp. 10-23.
(2009). "Artistas indígenas y afrocolombianos: entre las memorias y las cosmovisiones. Estéticas de la Resistencia", en Arte y estética en la encrucijada descolonial. Zulma Palermo, (Ed.). Buenos Aires, Argentina: Ediciones del Signo.

Barrera Vásquez, A. (2009). El teatro y la danza entre los antiguos mayas. Yucatán, México: Secretaría de Educación del Gobierno del Estado de Yucatán.

Bhabha, H. (2002). El lugar de la cultura, Buenos Aires: Manantial.

Cardoza Aragón, L. (Trad.). (1972). Rabinal Achí, El varón de Rabinal: ballet-drama de los indios Quichés de Guatemala. México: Editorial Porrúa.

Chavajay, B. (2015). HD: Haceres Decoloniales. “De los Haceres y los hacedores". (Pon.). En HD: Haceres Decoloniales. Bogotá, Colombia: Publicaciones Universidad Distrital Francisco José de Caldas.

Cornejo, K. (2013). "Indigeneity and Decolonial Seeing in Contemporary Art of Guatemala". En Fuse. 36(4). pp. 24-31.

Davis, A. (2002). "Other Landscapes, in Art, women, California". En 1950-2000: parallels and intersections. Diana Burgess Fuller y Daniela Salvioni. (Eds.). Los Angeles: University of California Press. pp. 45-78.

Estévez Trujillo, M. (2012). "Mis manos sonoras devoran la histérica garganta del mundo". En Miradas Alternativas desde la diferencia y subalternidades. Víctor Hugo Torres Dávila. (Ed.) Quito: Ediciones Abya Yala. pp. 43-67.

Ferrera-Balanquet, R. M. (2014). "Aiesthesis Descolonial Transmoderna". En Prácticas Artísticas e Imaginarios Sociales: XI Bienal de La Habana, Montes de Oca Moreda, D., Fernández Torres, López Rodríguez, B. V., y Portela, J. (Eds.). La Habana, Cuba: Centro de Arte Contemporáneo Wifrido Lam. pp. 79-88.

(2013). "Writing the Decolonial Mariposa Ancestral Memory", Caribbean In Transit, Issue 4. Virgina, Estados Unidos., pp. $38-43$

(1991). "The Videotapes of Latino Midwest Video Collective: A Manifest", Cinematograph, a journal of film and media art. 4., pp. 149-152.

Gentes, Ingo G., y Ruiz, S. A. (2008). "Challenges and perspectives of water governance and integrated water resource management in Bolivia/Retos y perspectivas de la gobernanza del agua y gestión integral de recursos hídricos en Bolivia". En European Review of Latin American and Caribbean Studies/ Revista Europea de Estudios Latinoamericanos y del Caribe 85., pp. 41-59. 
Glissant, É. (1997). Poetics of Relation. Ann Arbor: University of Michigan Press.https://doi.org/10.3998/mpub.10257

Gómez Moreno, P. P. (2015). Estéticas fronterizas: diferencia colonial y opción estética decolonial. Bogotá: Universidad Distrital Francisco José de Caldas.

(Curador) (2015). Haceres Decoloniales, exposición y evento académico, Sala de Exposiciones ASAB, Facultad de Arte ASAB, Universidad Distrital Francisco José Caldas. Bogotá, Colombia.

(2016). HD: Haceres decoloniales: prácticas liberadoras del estar el sentir y el pensar. Bogotá: Universidad Distrital Francisco José de Caldas.

Golitko, M., Meierhoff, J.s, Feinman, G. M., y Williams, P. R. (2012) Complexities of collapse: the evidence of Maya obsidian as revealed by social network graphical analysis. ANTIQUITY. 86., pp. 507-523 https://doi.org/10.1017/S0003598X00062906

Jáuregui, C. (2008). Canibalia. Canibalismo, calibanismo, antropofagia cultural y consumo en América Latina. Ensayos de Teoría Cultural. Madrid, Espa-a: Iberoamericana.

Kant, I. $(1767,2011)$. Observations on the feeling of the beautiful and the sublime and Other Writings. Patrick Frierson y Paul Guyer. (Eds. Trads.). Cambridge: Cambridge University Press.

Latorre, G. (2008). Walls of empowerment: Chicana/o indigenist murals of California, Austin, Texas: University of Texas Press.

Lockward, A. (Curadora). (2013). BE.BOP 2013: Decolonizing the Cold War, Berlín, Alemania.

Mignolo, W. D. (2007). “DELINKING", Cultural Studies, 21(2)., pp. 449-514. https://doi.org/10.1080/09502380601162647

(2005). The Idea of Latin America, Londres: Blackwell.

Mignolo, W. D. y Vázquez, R. (2013). “Decolonial Aesthesis:Colonial Wounds/Decolonial Healings". En Social Text/Periscope. Disponible en:

Monterroso, S. (2015). Correspondencia electrónica con el autor.

Mu-iz, I. (2007) “Más que pieles negras: Apuntes sobre el Cimarronaje Cultural en el Arte Caribe-o Contemporáneo," Contexto Latinoamericano: Revista de Análisis Político No. 6, pp. 173-179.

Robles Luna, M. (1989). Pinturaltura: Vermillion Blues Spilling, Reflections on the Works of Juana Alicia. Artist Monograph
Series. No. 2. San Francisco, California: Galería de la Raza, Studio 24.

Romero Flores, J. R. (2012). "Sensibilidades vitales, fiesta, color, movimiento y vida en el espacio festivo de Oruro-Bolivia". En Estéticas y opción decolonial, Walter D. Mignolo y Pedro Pablo Gómez. (Eds.). Bogotá, Colombia: Universidad Distrital José Francisco Caldas.

Pérez, L. E. (2007). Chicana Art: The Politics of Spiritual and Aesthetic Altarities, Durham: Duke University Press. https://doi. org/10.1215/9780822389880

Vázquez, R. (2011). "Modernity Coloniality and Visibility: The Politics of Time", Sociological Research Online. 14(4). Disponible en: http://www.socresonline.org.uk/14/4/7.html.

Walsh, C. (2011). Ełnoeducación e interculturalidad en perspectiva de Colonial. (Pon. 7 de septiembre). Cuarto Seminario Internacional "Etnoeducacion e Interculturalidad. Perspectivas Afrodescendientes" CEDET. Lima, Perú.

Walsh, C., y García, J. (2002). "El pensar del emergente movimiento afroecuatoriano. Reflexiones (des)de un proceso". En Estudios y otras prácticas intelectuales latinoamericanos en cultura y poder. Daniel Mato (Coord.).Buenos Aires: CLACSO.

Yampara Huarachi, S. (2011). "Cosmovivencia Andina. Vivir y convivir en armonía integral —Suma Qama-a". En Bolivian Studies Journal /Revista de Estudios Bolivianos. 18., pp. 1-22. https://doi.org/10.5195/BSJ.2011.42

\section{Vídeo}

Colectivo de Video Latino Midwest-Mérida (1992). Resistencia, en la serie Rock the Boat. Nueva York: Deep Dish TV.

\section{Instalación}

Lasch, P. (2010). Espejo Negro, Durham, NC: Nahser Museum of Art, Franklin Humanities Institute, Duke University. 